\title{
Research Paper: Effect of a Behavioral Support Program on the Social Skills of Male Children With Biomotor Disabilities
}

\section{*Masoume Pourmohamadreza Tajrishi ${ }^{1}$ (), Roghayyeh Tarrah Hamednezam² ${ }^{2}$, Guita Movallali ${ }^{1}$ (1)}

1. Pediatric Neurorehabilitation Research Center, University of Social Welfare and Rehabilitation Sciences, Tehran, Iran.

2. Department of Psychology and Exceptional Children Education, University of Social Welfare and Rehabilitation Sciences, Tehran, Iran.

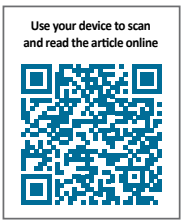

Cfteation Pourmohamadreza Tajrishi M, Tarrah Hamednezam R, Movallali G. [Effect of A Behavioral Support Program on the Social Skills of Male Children With Biomotor Disabilities (Persian)]. Archives of Rehabilitation. 2019; 20(2):98-113. http:// dx.doi.org/10.32598/rj.20.2.98

doj http://dx.doi.org/10.32598/rj.20.2.98

Received: 10 Jan 2019

Accepted: 24 May 2019

Available Online: $01 \mathrm{Jul} 2019$

\begin{abstract}
Objective Children with biomotor disabilities are influenced by negative social attitudes towards themselves; this is due to their problems in independence, self-reliance, and self-help skills. The people's attitudes and children's feedback towards their disability directly influence the adaptation of children. Some support programs can help these children to cope well with different social conditions. A behavioral support program is a new approach to promoting emotional and social competence in children. The program is adjusted as a pyramidal model to support everyone. It focuses on the promotion of health and provides services for children. Moreover, the program replaces appropriate social and communication skills with challenging behaviors (e.g. aggression and rulebreaking) and may improve effective communication and positive behaviors, and reduce negative behaviors in children. The present study aimed to determine the effect of the behavioral support program on the social skills of children with biomotor disabilities in Tehran City, Iran.

Materials \& Methods This was a quasi-experimental study with a pretest-posttest design and a control group. The study samples consisted of 28 children aged 5-7 years educating in the 2013-2014 academic year in special education centers in Tehran. The sample was purposefully selected. There are only three special centers in Tehran for children with biomotor disabilities. The sample ( 28 individuals) was selected according to the sample size formula, considering sample missing probability, and the inclusion and exclusion criteria. The subjects consisted of 14,6 and 8 individuals from the $16^{\text {th }}, 5^{\text {th }}$, and $3^{\text {rd }}$ educational districts, respectively. The students from $16^{\text {th }}$ educational district were allocated in the control group and those from the $5^{\text {th }}$ and $3^{\text {rd }}$ educational districts in the experimental groups. All students in the two experimental groups and control group were matched in terms of socioeconomic status and parent's educational level. Then, the parents and teachers of all groups completed the Social Skills Rating System (SSRS). The students of two experimental groups participated in 14 training sessions ( 3 days/week; each session: 40 minutes) and received the behavioral support program in addition to the conventional program of the center; the controls only received the center's routine program. Eventually, all parents and teachers of the subjects re-completed the SSRS after the last intervention sessions. The collected data were analyzed by the one-way Analysis of Covariance (ANCOVA).
\end{abstract}

Results The results of one-way ANCOVA for acquired data from SSRS (parent form) demonstrated that the behavioral support intervention significantly increased $(P<0.001)$ social skills (cooperation,

\section{* Corresponding Author:}

Masoume Pourmohamadreza Tajrishi, PhD.

Address: Pediatric Neurorehabilitation Research Center, University of Social Welfare and Rehabilitation Sciences, Tehran, Iran

Tel: +98 (21) 22180042

E-Mail: mpmrtajrishi@gmail.com 
Keywords:

Biomotor disability, Social skills, Behavioral support program assertiveness, self-control, and responsibility) in male students with biomotor disabilities. According to eta quotients obtained from the parents' evaluation, $82 \%, 63 \%, 82 \%, 66 \%$, and $67 \%$ of variations in social skills (cooperation, assertiveness, self-control, and responsibility) of children with biomotor disabilities could respectively be explained by the behavioral support intervention. The results of SSRS (teacher form) revealed that the participation of male students with biomotor disabilities in the intervention has significantly increased their social skills, cooperation, assertiveness, and self-control $(\mathrm{P}<0.001)$. Furthermore, according to eta quotients, $65 \%, 61 \%, 51 \%$, and $70 \%$ of variations in social skills, cooperation, assertiveness, and self-control of male students with biomotor disabilities could be respectively explained by participating in the behavioral support intervention sessions.

Conclusion The behavioral support program is a practical strategy for parents and specialists to reduce the social adjustment issues of children with biomotor disabilities. Therefore, the intervention should be considered in planning and policymaking for family training programs. Furthermore, using the behavioral support program along with the conventional training methods can promote social skills, assertiveness, self-control, and responsibility in children with biomotor disabilities. Thus, such programs can prevent ongoing social communication, emotional and academic problems, unemployment, social isolation, and withdrawal, developed due to biomotor limitations in these children. 
This Page Intentionally Left Blank 


\title{
تأثير برنامه حمايت رفتارى بر مهارتهاى اجتماعى بسران با كمتوانى جسمىحركتى
}

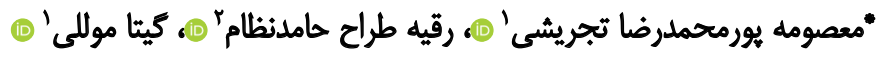 \\ 1- - مركز تحقيقات توانبخشى اعصاب اطفال، دانشكاه علوم بهزيستى و توانبخشى، تهران، ايران.

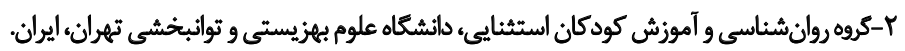

\begin{abstract}
حكبد

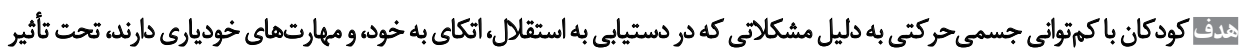

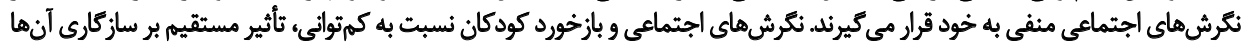

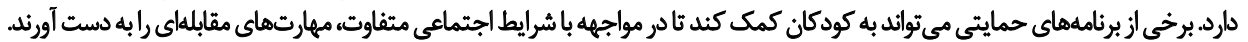

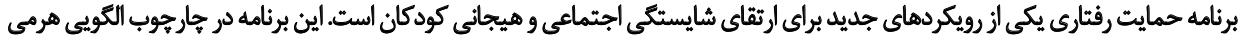

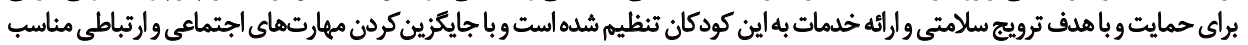

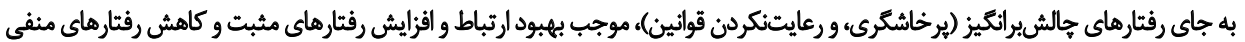

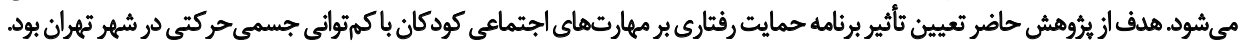

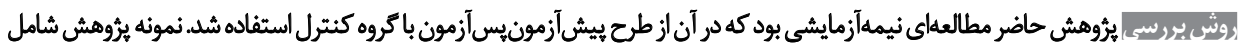

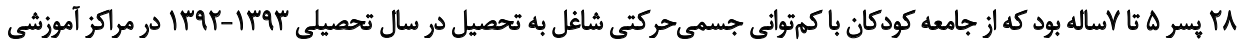

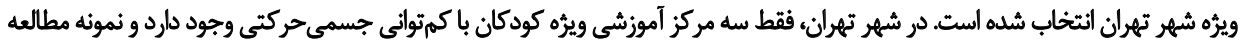

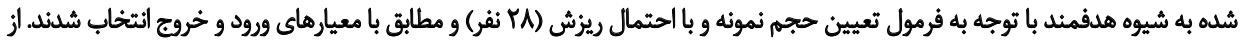

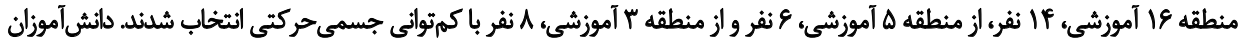

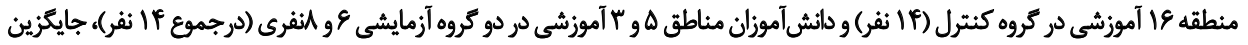

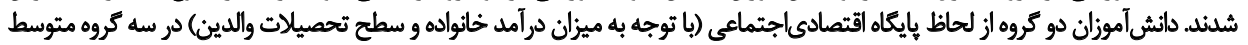

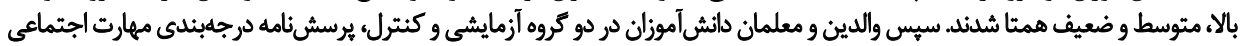

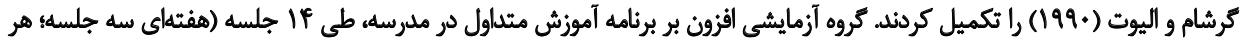

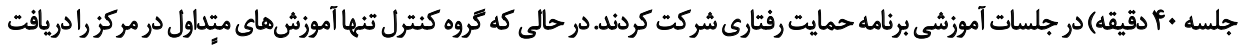

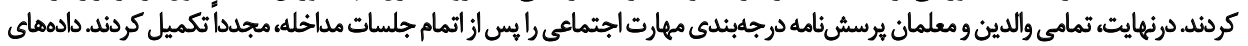

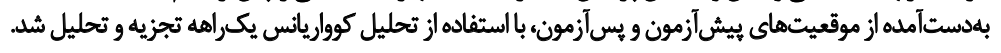

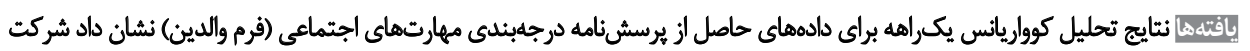

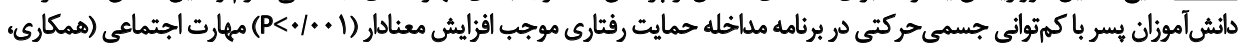

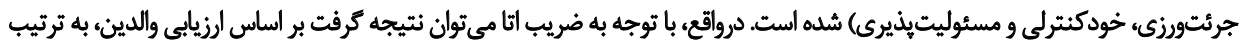

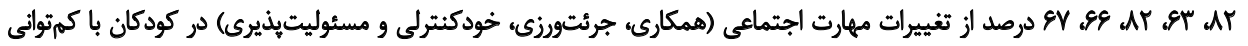

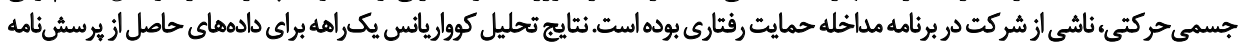

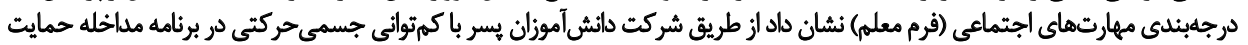

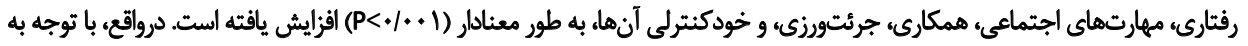

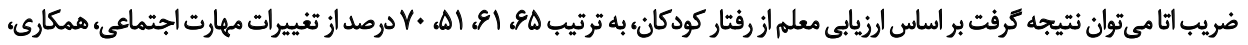

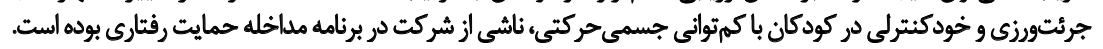

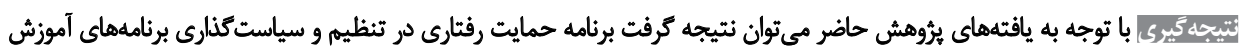

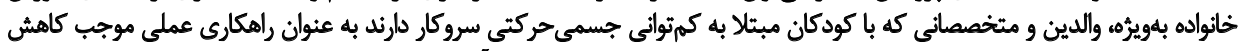

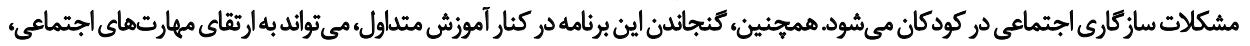

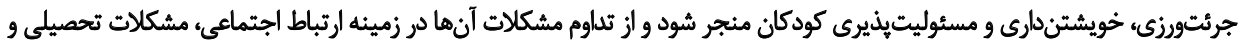

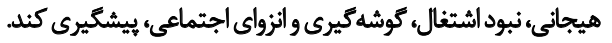

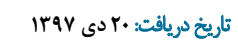

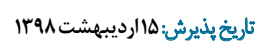

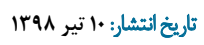

كليدواثرها:

كمرتوانى جسمى حركتى،

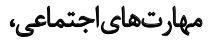
برئامه حمايت رفتارى

ㄷ..

$$
\begin{aligned}
& \text { : نويسينده مسيئول: }
\end{aligned}
$$

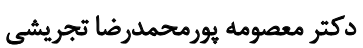

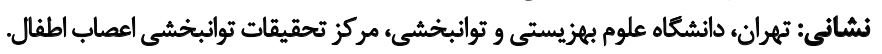

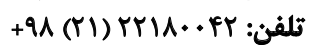

$$
\begin{aligned}
& \text { رايانامه: mpmrtairishi@gmail.com }
\end{aligned}
$$


مشكلات بينفردى، ارتباط اجتماعى ضعيف، مشكل در اكتساب

مقلمه

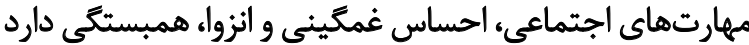

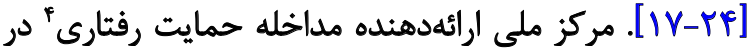

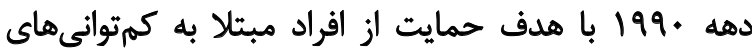

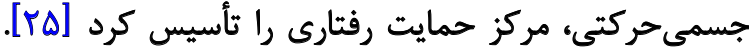

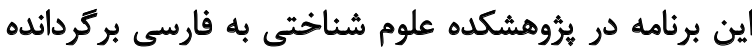

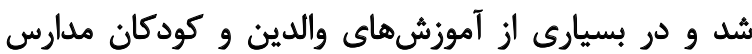
استثنايى به كار رفته است.

به طور خلاصه مى توان كفت كه الكوى هرمى به عنوان يك

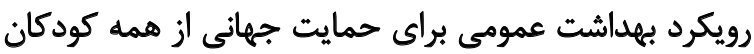

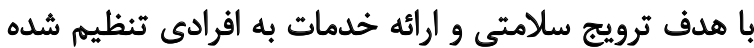

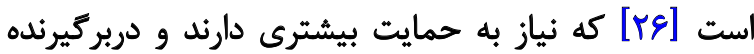

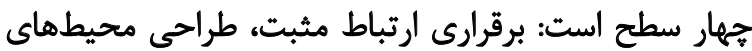

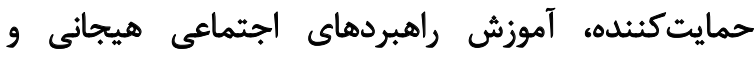
مداخلات فشرده انفرادى [ [Tr.].

در اين برنامه، يك الكوى هرمى از حمايت رفتارى براى إئ

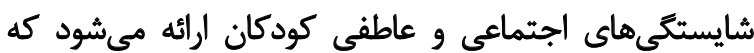

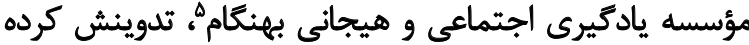

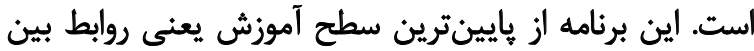

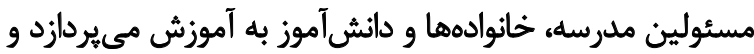

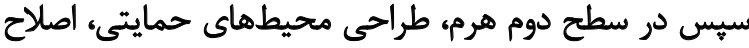

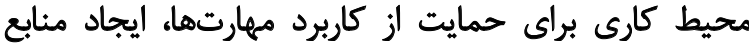

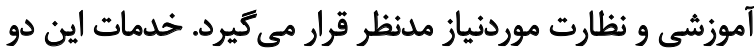

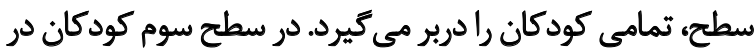
معرض خطر، برنامه مهارت اجتماعيى رادي ادريافت مى كنيند.

در الكوى هرمى مهارتهاي اجتماعى هيجانيى اصلى موردنياز

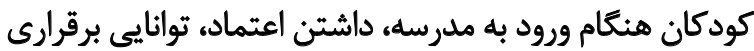
روابط خوب با همسالان، تمركز و يشتكار در انجام اندام تكاليف

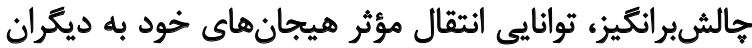

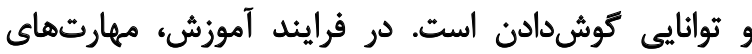

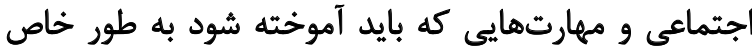

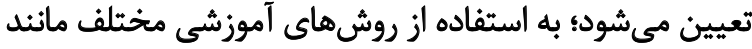

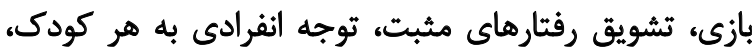

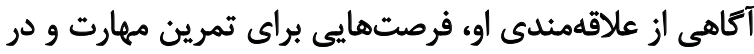

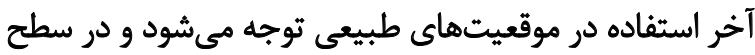

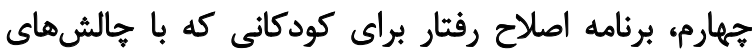

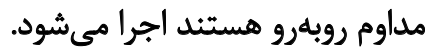

در الكَوى هرمى، مهارتهاى اجتماعى هيجانى اصلى موردنياز

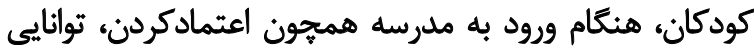

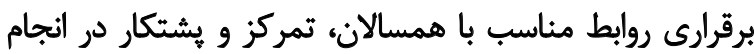

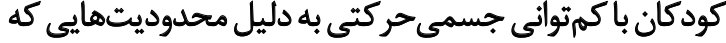

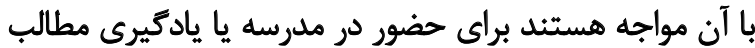

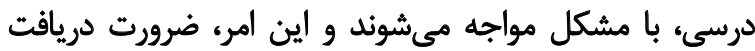

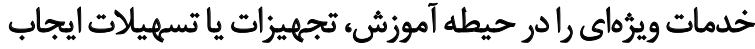

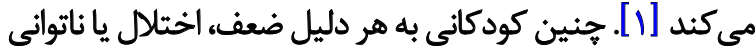

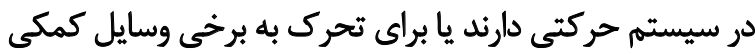

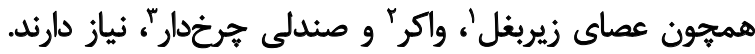

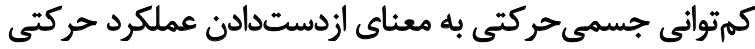

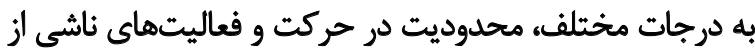

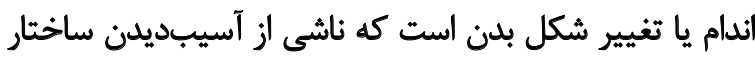

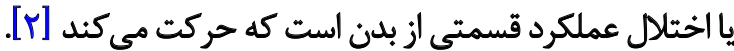
طبق كزارش سازمان ملل متحد [ب]، · •ا درصد از جمعيت

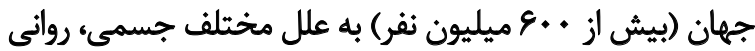

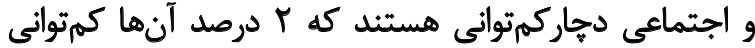

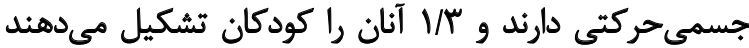

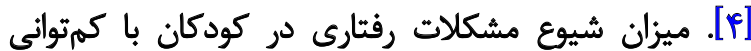

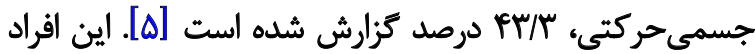

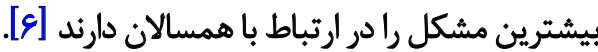
شواهد بثروهشى نشان مىدهد كودكان مبتلا به كمتوانى

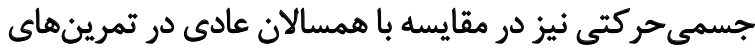

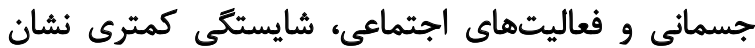

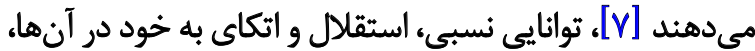

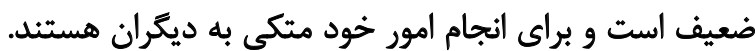

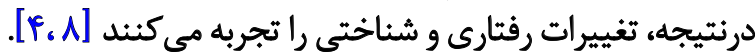

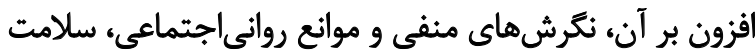

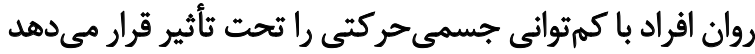

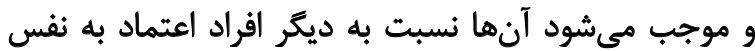

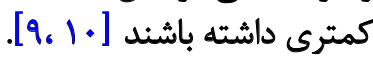
مهارتهاى اجتماعى از جمله برقرارى ارتباط، حل مسئله،

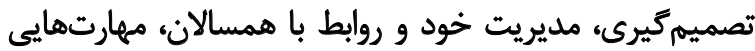

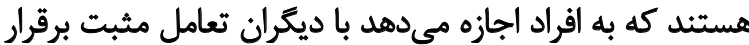

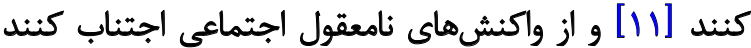

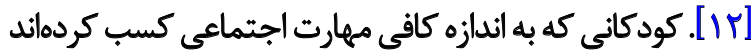

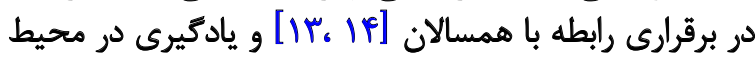

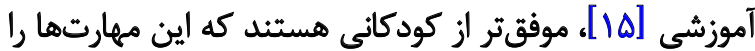

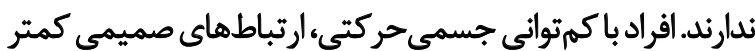

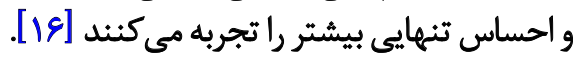
به طور كلى، كمتوانى جسمى حركتى با علائم افسردگى، 


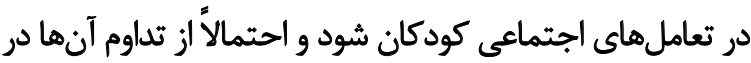

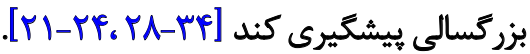

همجنين، مى توان در صورت مؤثربودن برنامه حمايت رفتارى

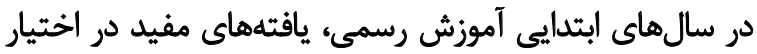

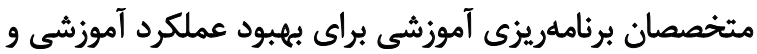

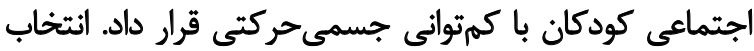

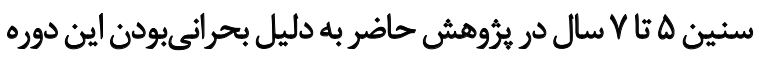

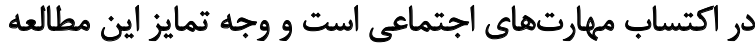

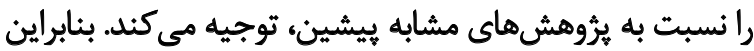

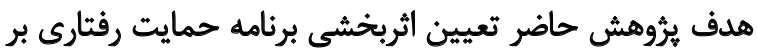

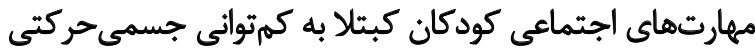

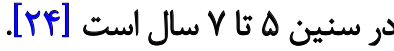

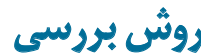

يُروهش حاضر يك مطالعه نيمهآزمايشى با طرح بيش بيش آزمون

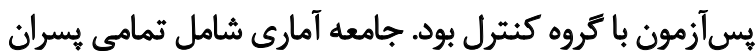

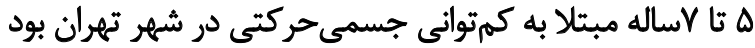

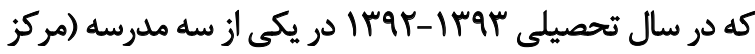

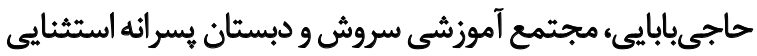

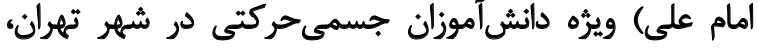
مشغول تحصيل بودند. - ماند

با استفاده از روش نمونهكيرى هدفمند، از سه مدرسه ويروهُ

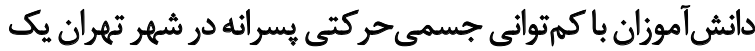

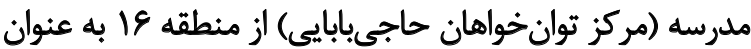

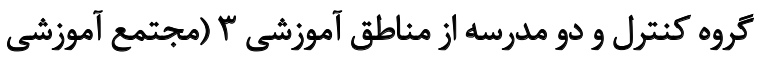

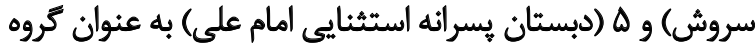

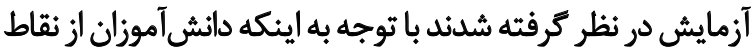

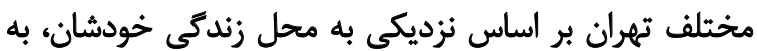

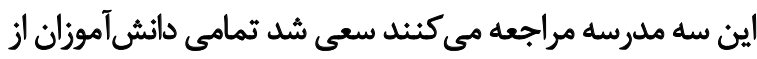

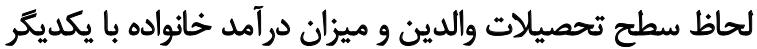

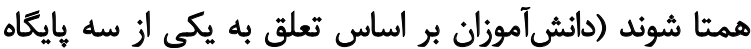

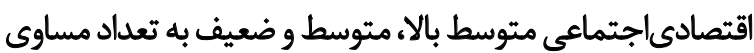

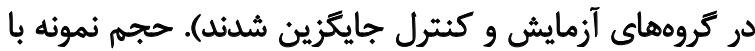

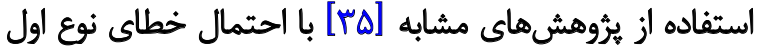

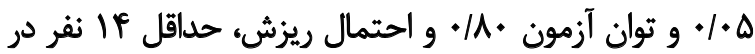

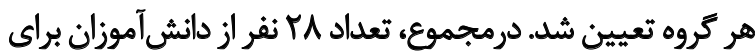

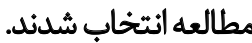
ابزئار تردآورى دادهها

\section{يرسش نامه درجهبندى مهارتهاى اجتماعى"}

در يُروهش حاضر از يرسشنامه درجهبندى مهارتهاى

7. Social Skills Rating System (SSRS)

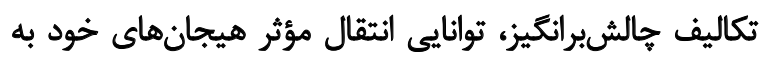

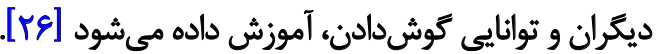

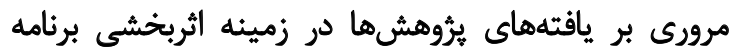

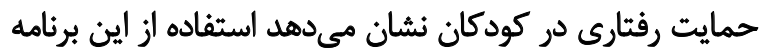

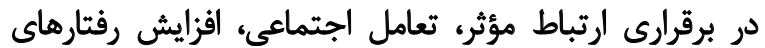

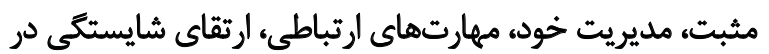

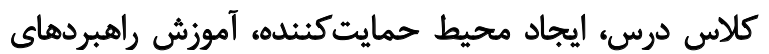

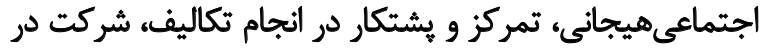

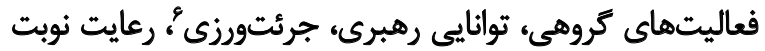

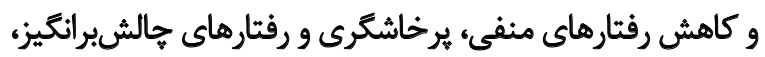

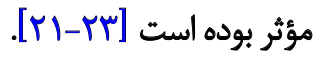

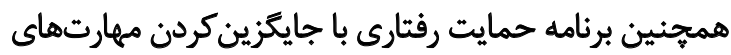

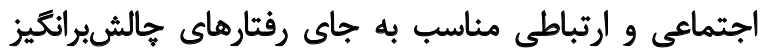

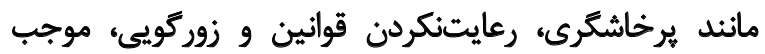

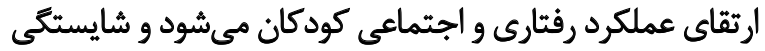

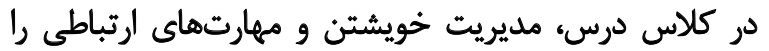

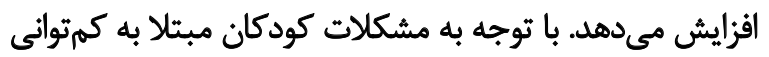

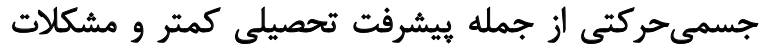

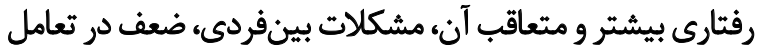

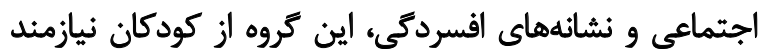

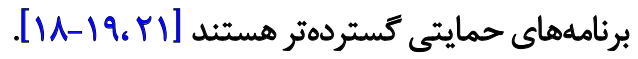

با توجه به فقدان يُروهشهاي داخلى كه اثربخشى برنامه

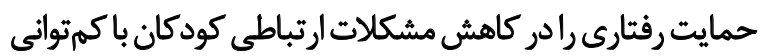

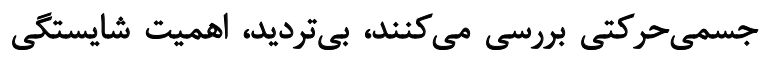

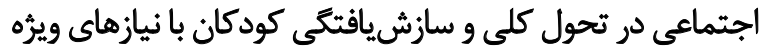

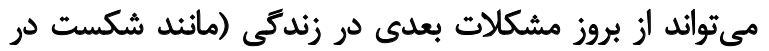

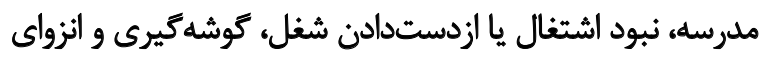
اجتماعى) جلوكيرى كند.

از آنجايي كه آموزش مهارتهاي اجتماعى موجب كاهش

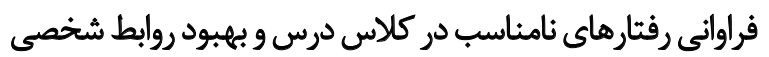

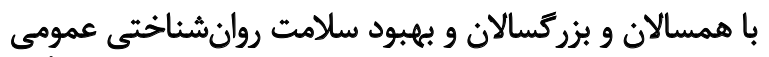

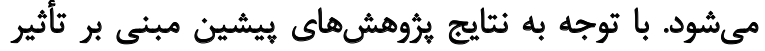

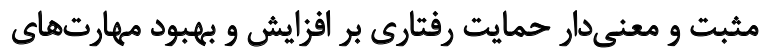

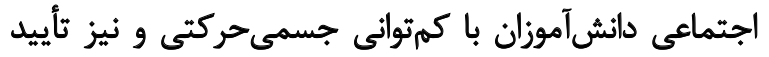

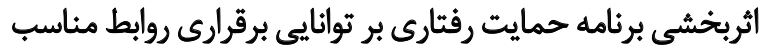

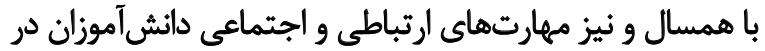

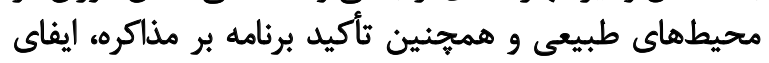

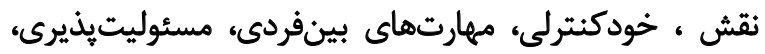

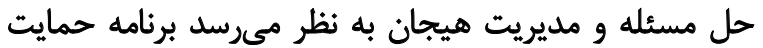

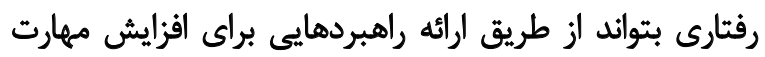

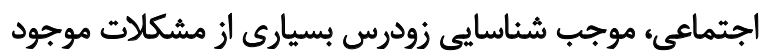

6. Assertiveness 
(•أسؤال براى هركدام از سه مؤلفه همكارى، جرئتورزى، خودكنترلى) و فاقد مؤلفه مسئوليتيذيرى است مئل فرم دانشآموز مقياسى خودكزارشى است كه براى سنين

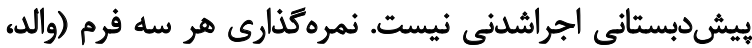

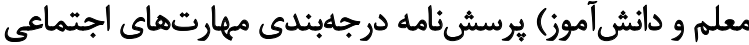

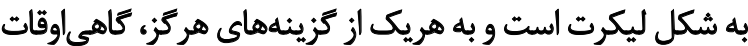

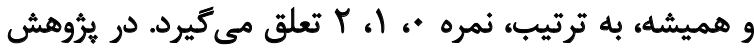

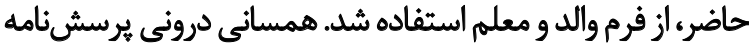

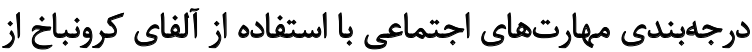

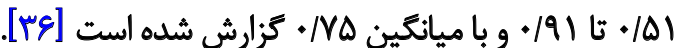

فلانكان "1 و همكاران در بررسى روايى همكراى اين مقياس

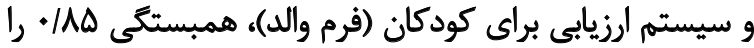

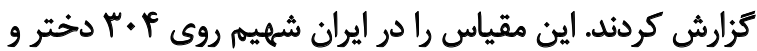

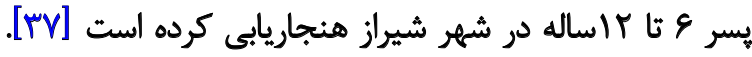

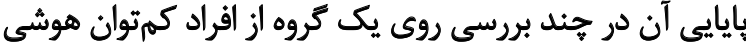

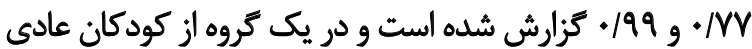

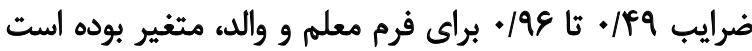

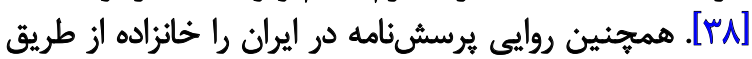

14. Flanagan
اجتماعى براى اندازهيرى مهارتهاى اجتماعى دانشآموزان

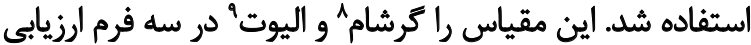

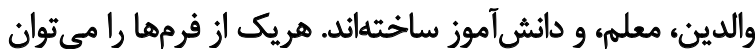

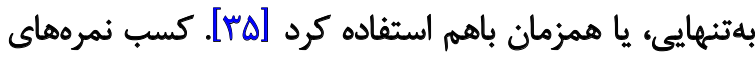

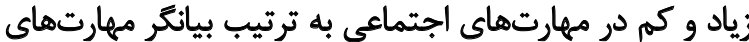
اجتماعى قوى و ضعيف است.

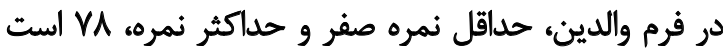

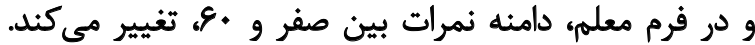

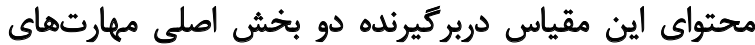

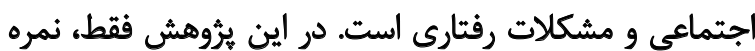

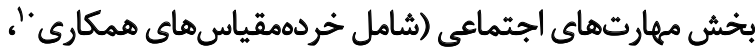

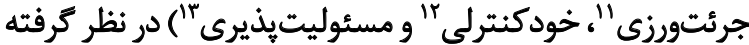

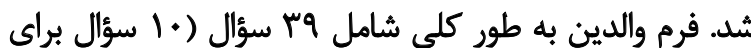

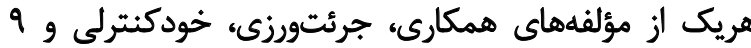
سؤال براى مؤلفه مسئوليتيذيرى) و فرم معلم شامل • ب سؤال

\section{Gresham}

9. Elliot

10. Cooperation

11. Assertion

12. Self-control

13. Responsibility

جدول (. محتواى برنامه حمايت رفتارى به تفكيك جلسات آموزشى

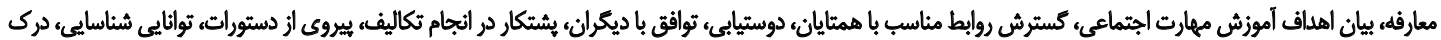

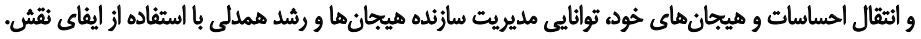

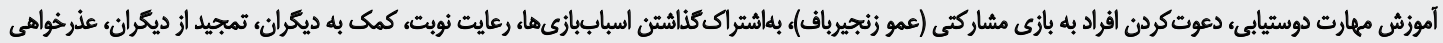
در زمان هناسب، همدلى با ديكران دمان.

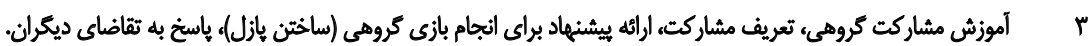

أموزش كمك كردن به ديكران و ثقاضاى كمككردن، نمايش جكونكى انجام كار با بيانكردن مراحل آن فعاليت به دوست خود و عمل كردن به آن، كمك به دوست خود در مواقع يريشائى.

أموزش قُواعد مانثد رعايت نوبت، نامكثلارى قانون، نمايش عمل به قانون و كمك به كودى در تعميم قانون نوبت كيرى.

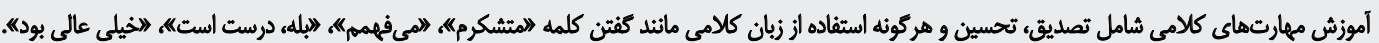

آموزش مهارث غيركلامى ماندل دستدادن، درآغوش كرفتن، ضربهزن به يشت فرده ينجهبهينجهزدن.

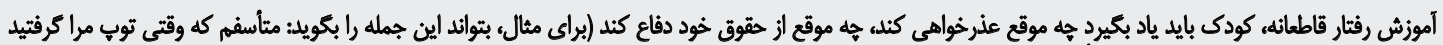

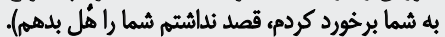

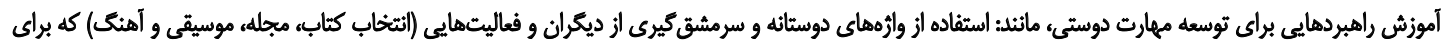
ايجاد مهارت دوستى مى توان استفاده كرد.

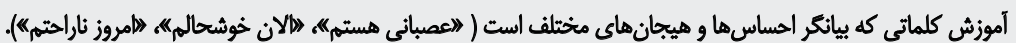

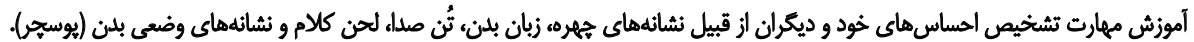

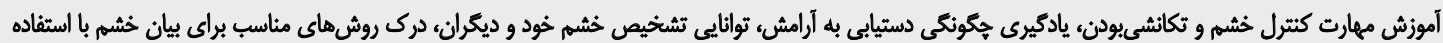

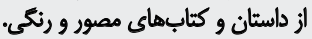

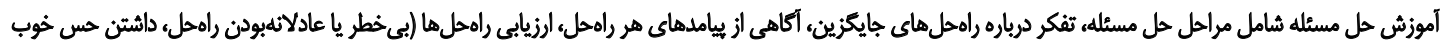

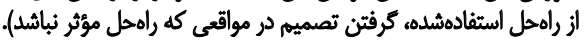


كردند. به دليل اينكه كروه آزمايش از دو مدرسه انتخاب شده

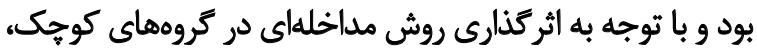
دو تروه آزمايش شكل ترفت (يك ترون

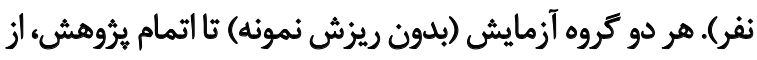

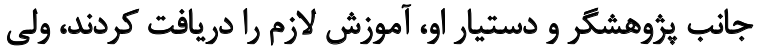
به تروه كنترل فقط برنامه متداول مركز ارائه شد.

برنامه حمايت رفتارى بر اساس الكوى مؤسسه يادكيرى

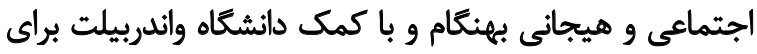

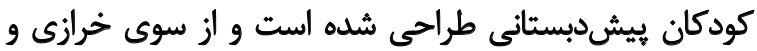

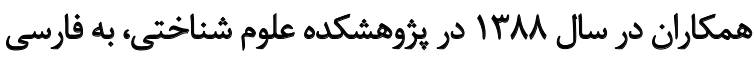

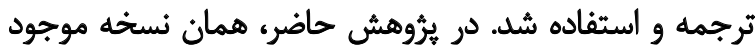

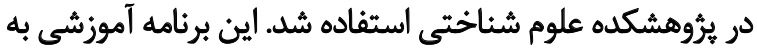

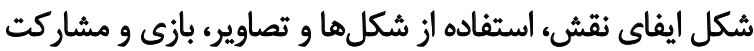

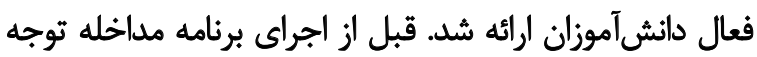

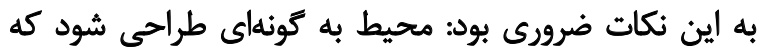

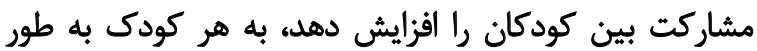

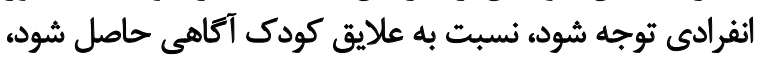

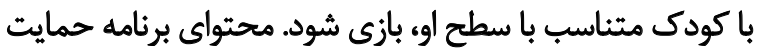
رفتارى در جدول شماره ال ارائه شده است.

به منظور رعايت ملاحظات اخلاقي، محتواى جلسات مداخلهاي

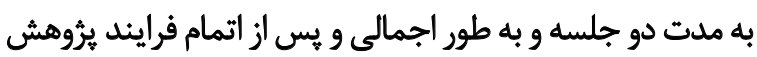

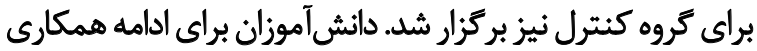

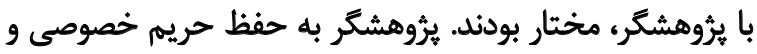

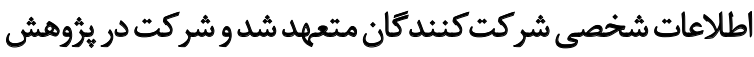

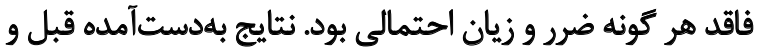

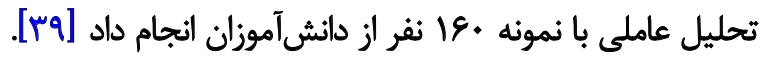

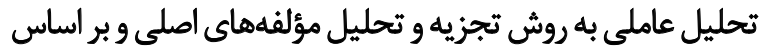

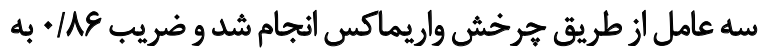

دست آمد كه معنادار و رضايتبخش بورد [f.] ووش اجرا

يس از هماهنكى با سازمان آموزش و يرورش استثنايى شهر

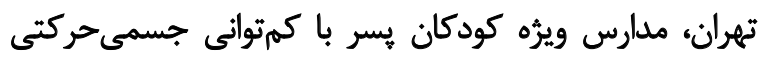

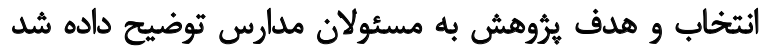

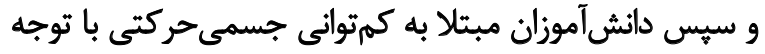

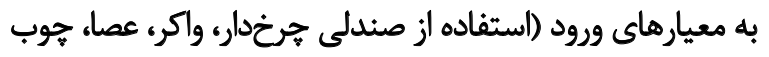

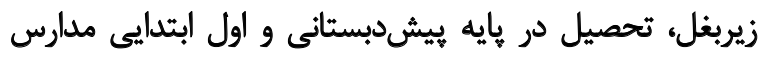

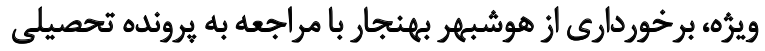

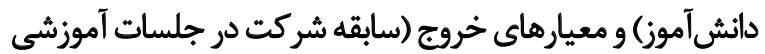

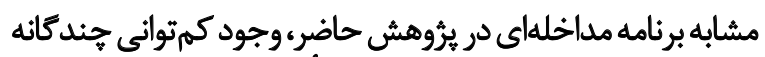

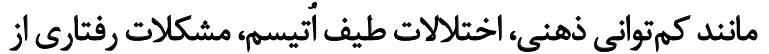

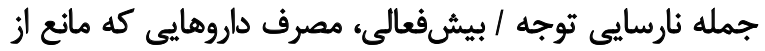

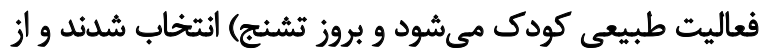

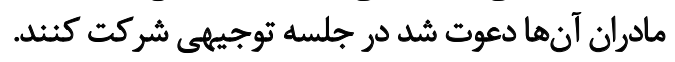

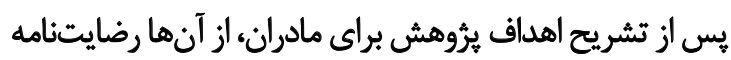

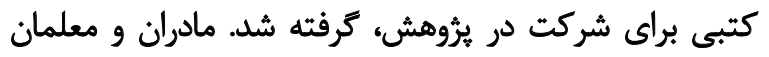

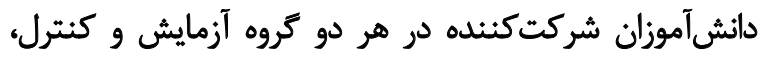

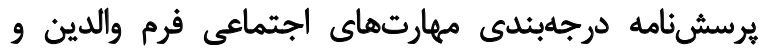

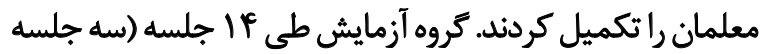

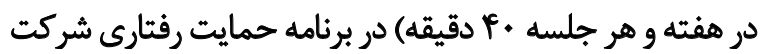

جدول ب. ميانكين و انحراف استاندارد متغير مهارتهاى اجتماعى و مؤلفههاى آن بر اساس فرم والدين

\begin{tabular}{|c|c|c|c|}
\hline يس آزمون & ييش آزمون & \multirow{2}{*}{ مثغير } & \multirow{2}{*}{ كروه } \\
\hline \multicolumn{2}{|c|}{ ميانكيند|تحراف استاندارد } & & \\
\hline$\varepsilon T / \cdot Y \pm \bowtie / R Y$ & $r \in / T I \pm N q$ & مهارت اجتماعى & \\
\hline $1 Q / T q \pm T / T V$ & $V / * \pm m / M f$ & همكارى & \\
\hline$|8 / * \pm V / 0|$ & S/MQ $\pm Y / A Y$ & جرتثورزى & آزمايش \\
\hline$|\theta / *+ \pm| / \Delta \mid$ & $V / F r \pm r / \& \Delta$ & خودكنثرلى & \\
\hline $\mid F / 1 F \pm r / \Delta F$ & $\Delta / M) \pm r / A r$ & مستوليتيذيرى & \\
\hline 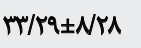 & $\Pi T / N \in \pm N \Delta$. & ههارت اجتماعى & \\
\hline$N \Delta V \pm r / q$. & $N \Delta \cdot \pm r / q T$ & همكارى & \\
\hline$N q T \pm Y / 18$ & $N N E \pm Y / \cdot V$ & جرثتورزى & كثترل \\
\hline$N F T \pm r / E V$ & $N R T \pm M / R T$ & خودكنترلى & \\
\hline $18 / \% 9 \pm \% / 10$ & $V / q T \pm r / I V$ & مسئوليتيذيرى & \\
\hline
\end{tabular}


جدول ب. ميانكين و انحراف استاندارد متغير مهارتهاى اجتماعى و مؤلفههاى آن بر اساس فرم معلم

\begin{tabular}{|c|c|c|c|}
\hline \multicolumn{2}{|c|}{ ميانكين +اتحراف استاندارد } & \multirow{2}{*}{\multicolumn{2}{|c|}{ متغير }} \\
\hline سـأزمون & بيشآزمون & & \\
\hline$P V / \Delta Y \pm Y / .8$ & $19 / \Delta+ \pm V / V \Delta$ & مهارت اجتماعى & \multirow{4}{*}{ أزمايش } \\
\hline $\mid \mathscr{V} \cdot V \pm T / T V$ & $V / r g \pm r / \cdot \Delta$ & همارى & \\
\hline $1 \Delta / V \Delta \pm T / T Y$ & $g / r q \pm r / q$ & جرثتورزى & \\
\hline$|E / M| \pm / M$ & D/NDTRES & خ خودكتترلى ل & \\
\hline$r V / r t \pm I r / r V$ & $T V / P F \pm I T / F T$ & مهارت اجتماعى & \multirow{4}{*}{ 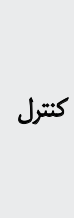 } \\
\hline$V / N I \Psi / T A$ & VRqDF/FT & همارى & \\
\hline$V / \cdot . \pm \Delta / 19$ & $V / \cdot V \pm \Delta / T)$ & جرثتورزى & \\
\hline$g / M \pm r / A Y$ & $q / V q \pm r / A q$ & خودكنترلى & \\
\hline
\end{tabular}

توانبخننى

جدول ع. بررسى عادىبودن توزيع نمرهها با استفاده از آزمون شاييروويلك

\begin{tabular}{|c|c|c|c|c|c|}
\hline \multicolumn{3}{|c|}{ شاييروويلك } & \multirow{2}{*}{ كروه } & \multirow{2}{*}{ قرم } & \multirow{2}{*}{ مثغير } \\
\hline سطح معنادارى & درجه آزادى & مقدار & & & \\
\hline.$/ 11$ & if &.$/ 1999$ & آزمايش & \multirow{2}{*}{ والد } & \multirow{4}{*}{ مهارت اجتماعى } \\
\hline$\cdot M$ & if &.$/ 199$ & كنترل & & \\
\hline$\cdot \mathrm{MA}$ & if & .1499 & أزمايش & \multirow{2}{*}{ معلم } & \\
\hline $.1 \Delta \Delta$ & if &.$/ 199$ & كتترل & & \\
\hline
\end{tabular}

توانبخننى

در ميانكين متغيرهاي مذكور در كروه كنترل (به استثناي مؤلفه

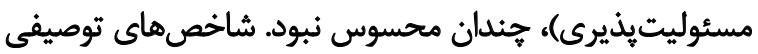

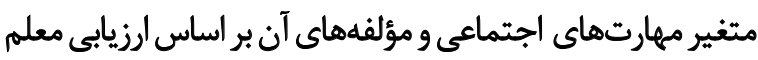

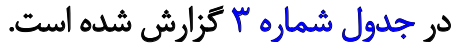

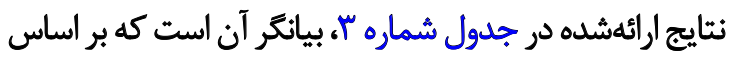

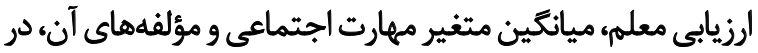

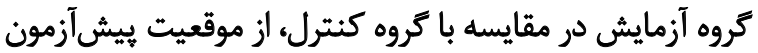

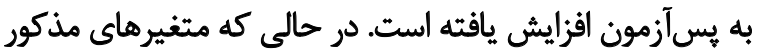

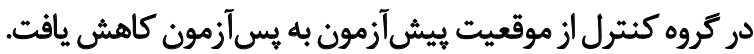
به منظور بررسى اين فرضيه كه برنامه حمايت رفتارى موجب

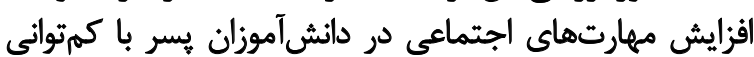

بعد از برنامه حمايت رفتارى با استفاده از شاخصهاي توصيفى و

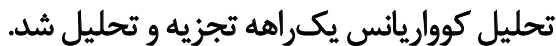

Latôt

ميانكين و انحراف استاندارد سن دانشآموزان كروه آزمايش و و

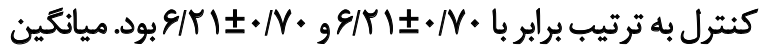

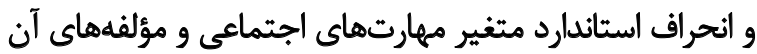

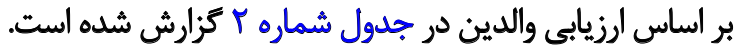

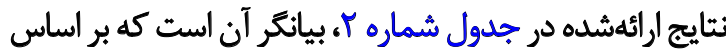

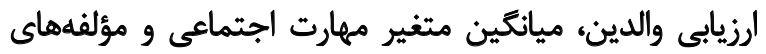

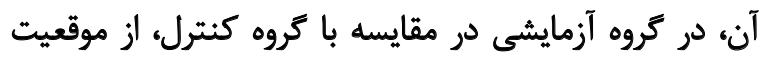
ييش آزمون به يس آزمون آفزايش يافته است. در حالى كه تغيير

جدول ه. نتايج آزمون لون براى بررسى همكنى واريانس نمرات درون كروهى

\begin{tabular}{|c|c|c|c|c|}
\hline سطح معنادارى & df2 & df1 & $\mathbf{F}$ & متغير مهارت اجتماعى \\
\hline .19 & te & 1 & $r / * 1$ & فرم واللد \\
\hline.$/ \pi$ & te & 1 & $1 / \pi$ & فرم معلم \\
\hline
\end{tabular}


جدول 7. خلاصه نتايج تحليل كوواريانس يكراهه براي مقايسه ميائكين مهارتهاي اجتماعى و مؤلفههاى آن در دو كروه

\begin{tabular}{|c|c|c|c|c|c|c|c|}
\hline توان أزمون & ضريب اتا & سطح معنادارى & $\mathbf{F}$ & ميانكين مجذورات & منيع تغيير & 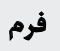 & مثغير \\
\hline 1 &.$/ 44$ & $<\cdot 1 . .1$ & ITav/M & 9790.119 & ييش آزمون & \multirow{2}{*}{ والد } & \multirow{4}{*}{ مهارت الجتماعى } \\
\hline 1 & - /AT & $<+1 . .1$ & $|W N|$ & $\Delta A+. / M T$ & كروه - اه & & \\
\hline 1 &.$/ 9 \%$ & $<.1 .01$ & $M T / F \Delta$ & mTrlo. & ييش آزمون & \multirow{2}{*}{ معلم } & \\
\hline 1 & .180 & $<+1 \cdot+1$ & $P V / V \Delta$ & PVAP/INT & S & & \\
\hline 1 &.$/ 28$ & $<.1 . .1$ & DENTY & $r q f /$ If & ييش آزمون & \multirow{2}{*}{ 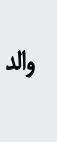 } & \multirow{3}{*}{ همكارى } \\
\hline 1 &. & $<\cdot 1 . .1$ & $F \Delta / .1$ & $\mathrm{rIQ} / \mathrm{AY}$ & كروه & & \\
\hline 1 & .191 & $<.1 . .1$ & $\begin{array}{l}\text { MY/.V } \\
r \cdot / r o\end{array}$ & $\begin{array}{l}r q . / \pi T \\
\text { PMAq }\end{array}$ & يش كرآزمون & مeم & \\
\hline 1 & .194 & $<.1 . .1$ & $\pi+1 / \%$. & FATE/Tq & ميش آزمون & \multirow[t]{2}{*}{ والد } & \multirow{4}{*}{ جرنتورزى } \\
\hline 1 & - IAT & $<. / .01$ & $\| \Delta / r A$ & $r+1 / r q$ & og & & \\
\hline 1 &.$/ M$ & $<+1 . .1$ & $W E / F \mid$ & THSE/Tq & ييش آزمون & \multirow[t]{2}{*}{ معلم } & \\
\hline.$/ 99$ &.$|A|$ & $<\cdot 1.01$ & $\mathrm{re} / \mathrm{M}$ & $018 / 79$ & 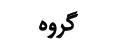 & & \\
\hline 1 &.$/ 2 \Delta$ & $<+1 . .1$ & $\Delta W E$. & PIW/Yq & ييشآزمون & \multirow{2}{*}{ 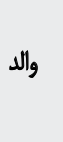 } & \multirow{4}{*}{ خودكنترلى } \\
\hline 1 & .188 & $<. / . .1$ & PQ/FQR & $r \cdot 1 / r q$ & S & & \\
\hline 1 & ( & $<\cdot 1 . .1$ & $\mathrm{raN} \cdot \mathrm{V}$ & rea.1.r & ييش آزمون & \multirow[t]{2}{*}{ مeملم } & \\
\hline 1 &.$/ v$ & $<.1 . .1$ & $91 / F Y$ & ETI/VA & 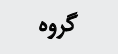 & & \\
\hline 1 &.$/ 9 \Delta$ & $<\cdot 1 \cdot .1$ & $\Delta 1 . / Q T$ & riw/ra & ييش آزمون & \multirow[t]{2}{*}{ 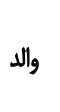 } & \multirow[t]{2}{*}{ مستوليتيذيذيرى } \\
\hline 1 &.$/ 8 Y$ & $<+1 . .1$ & $\Delta T / N E$ & $M T / N F$ & كروه & & \\
\hline
\end{tabular}

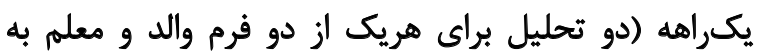
تفكيك) استفاده شد (جدول شماره 9).

بر اساس نتايج مندرج در جدول شماره ه هميتوان نتيجيه

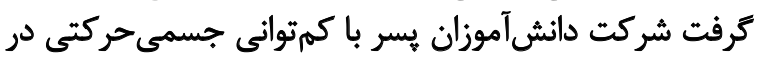

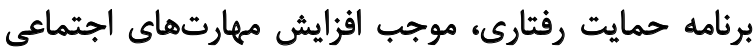

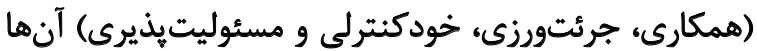

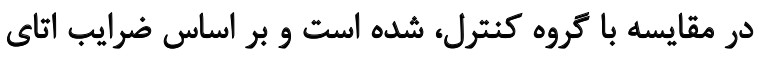

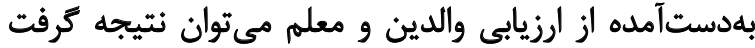

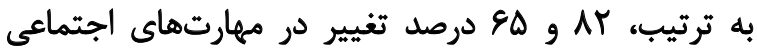

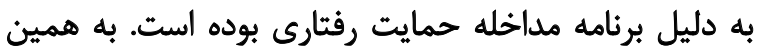

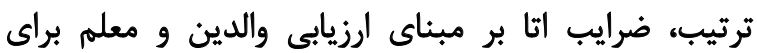

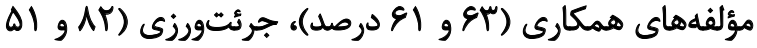

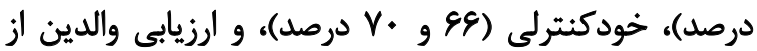

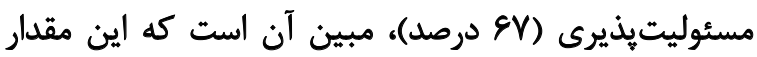

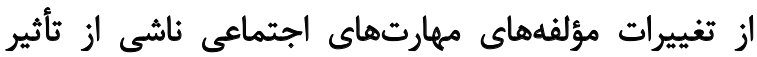

جسمى حركتى مىشود، از تحليل كوواريانس يكراهـ استفاده

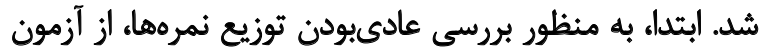

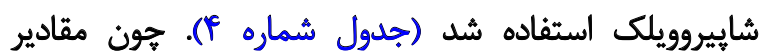

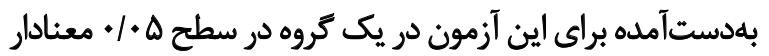

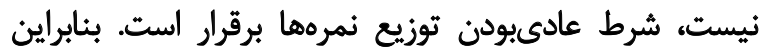

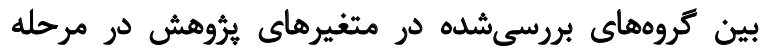

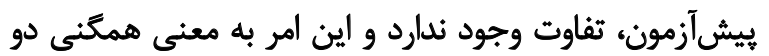
كروه در مرحله بيش آزمون است.

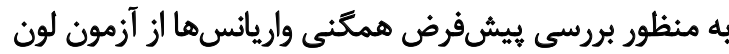

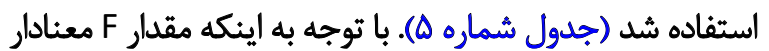

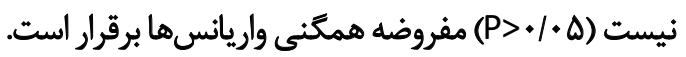
به منظور آزمودن فرضيههاى ثروهش مبنى بر اينكه برنامه

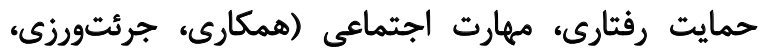

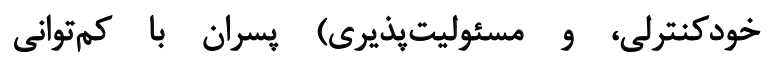
جسمى خركتى را افزايش مىدهد، از تحليل كوواريانس بلني 
رفتّارهاى كارآمدترى را نشان دهند. درنزهايت، اين توانياي را به

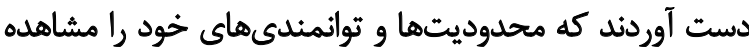

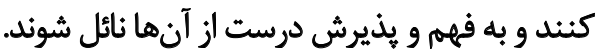
بنابراين، مى توان نتيجه كرفت برنامه حمايت رفتارى با تأكيد

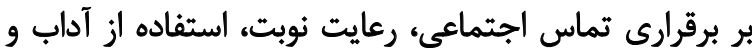

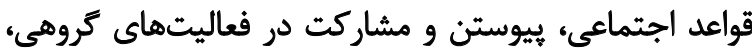

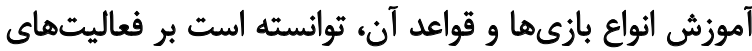

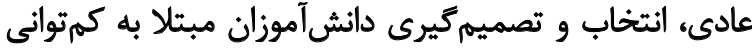

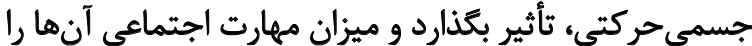

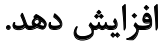

يافته ديكر يثوهش، حاكى از تأثير برنامه حمايت رفتارى

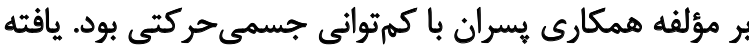

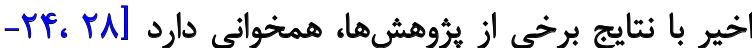

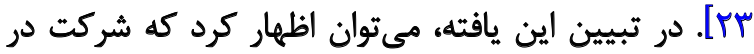

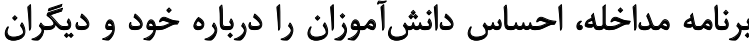

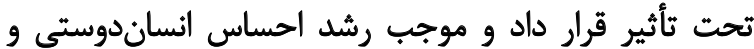

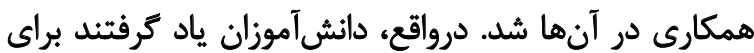
تعامل با همسالان، مهارتهاي بينفردى دان (از جمله، همكارى)

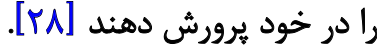
يكى ديكر از يافتههاى ثروهش، بيانكر آن است كه برنامه

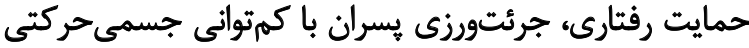

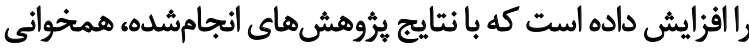

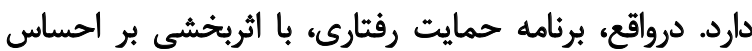

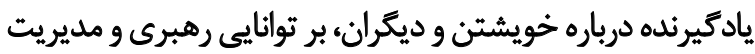

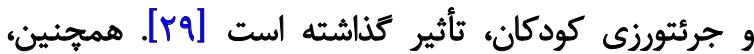

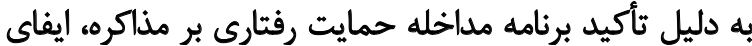

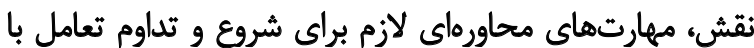

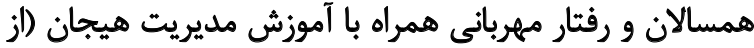

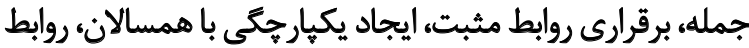

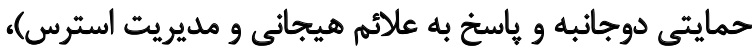

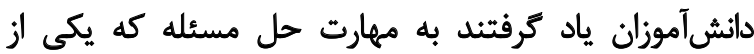

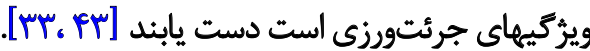
درواقع، دانشآموزان يّ إز دريافت مداخله حمايت رفتارى

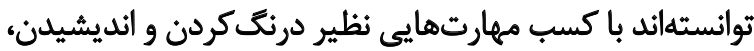

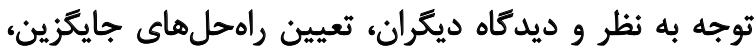

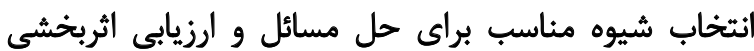

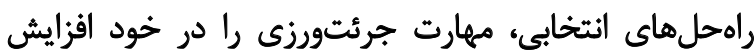

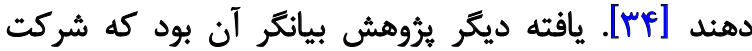

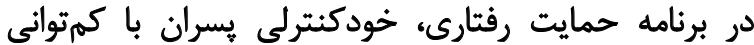

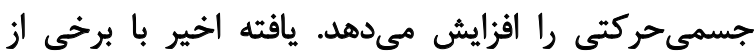

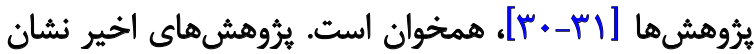
دادهاند كه آموزش حمايت رفتارى بر نوع شيوه مقان المثله تأثير
مداخله برنامه حمايت رفتارى بر يسران مبتلا به كمثتوانى جسمى حركتى، بوده است.

بـ

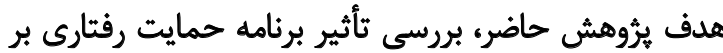

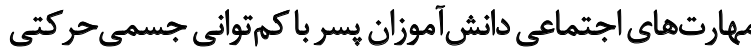

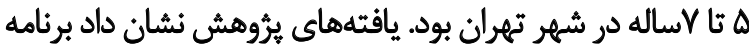

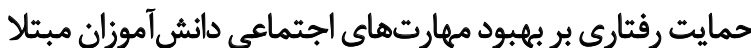

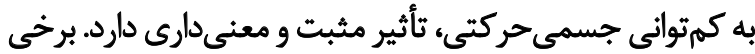

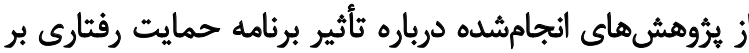

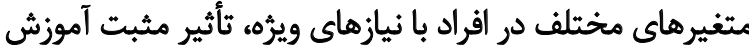

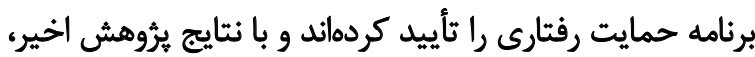

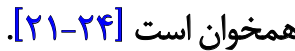

نخستين يافته ثئوهش حاضر نشان داد استفاده از برنامه

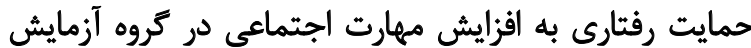

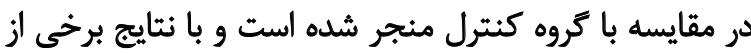

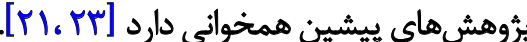

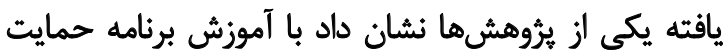

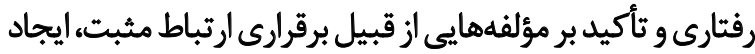

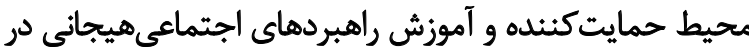

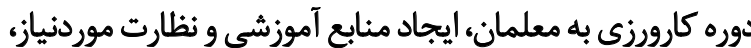

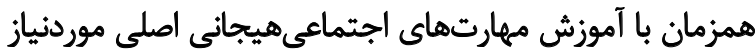

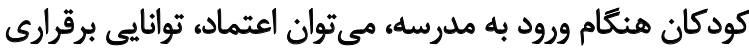

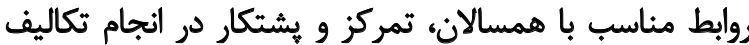

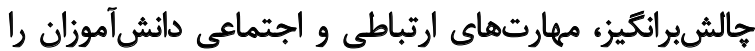

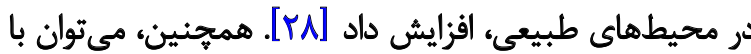

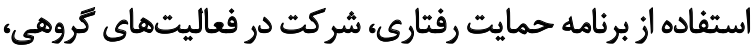

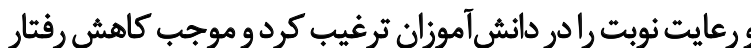

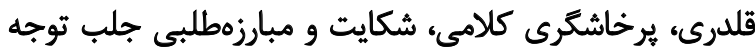

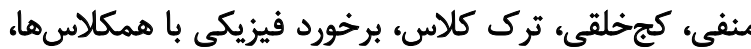

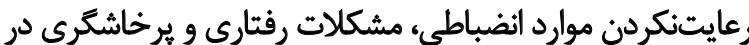

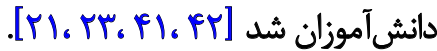

در تبيين يافتههاى يروهش مى توان اظهار كرد كه ارتباطهاى

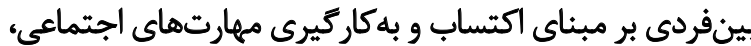

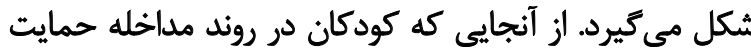

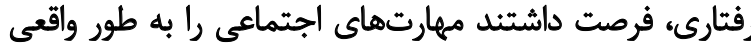

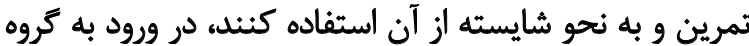

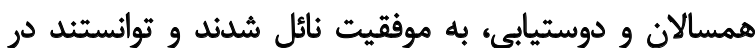

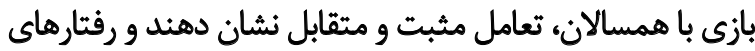

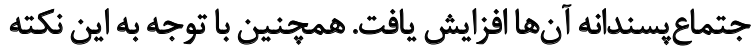

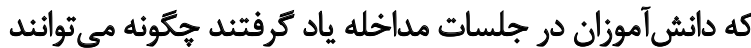

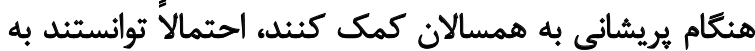

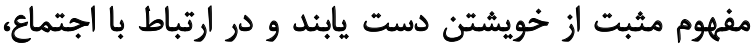


كمتوانى جسمى حركتى بيشكيرى كند و نقش مؤثرى در كاهش

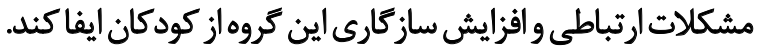

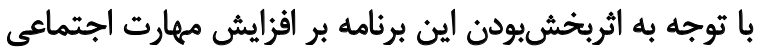

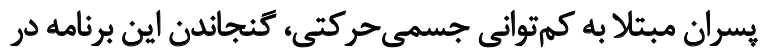

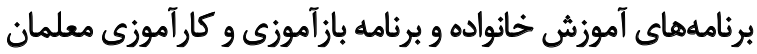

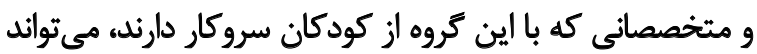

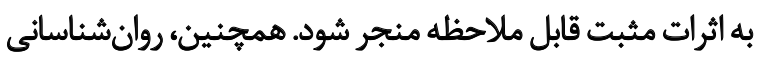

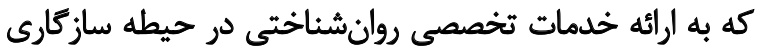

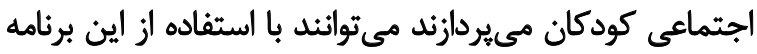

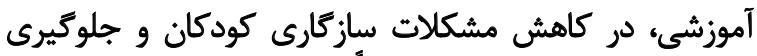

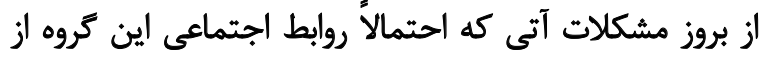
كودكان را به مخاطره مىاندازد، نقش مؤثر ايفا كنيند.

با توجه به تعداد اندى دختران مبتلا به كمثرتوانى

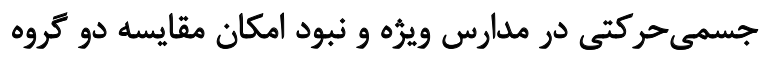

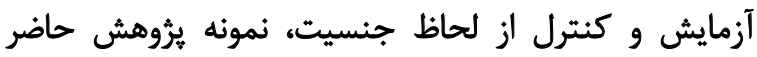

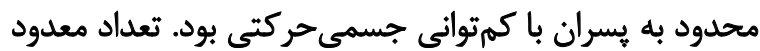

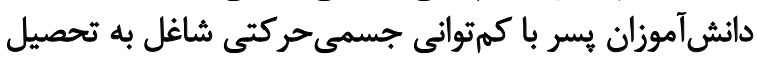

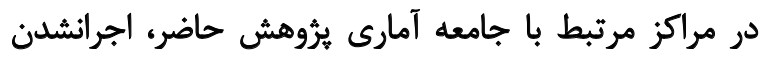

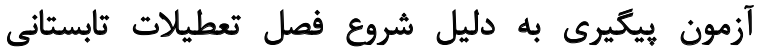

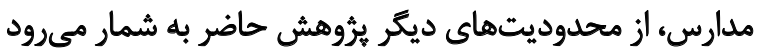

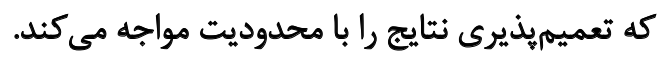

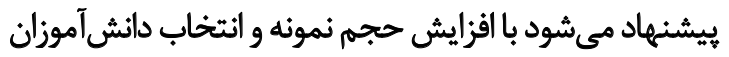

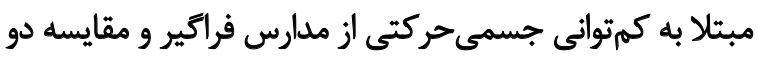

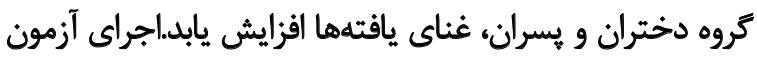

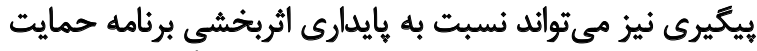

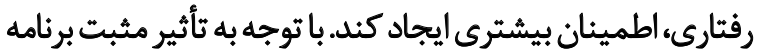

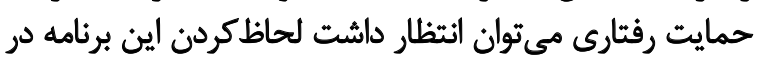

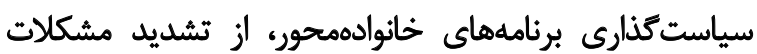

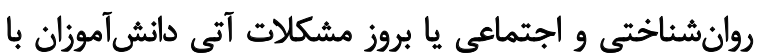
كمتوانى جسمى حركتى جلوكيرى مي كند. بروز مثلات آت

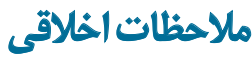

\section{ييروى از اصول انخالق هثوهشش}

به منظور رعايت ملاحظات اخلاقى به مسئولين مراكز مربوطه

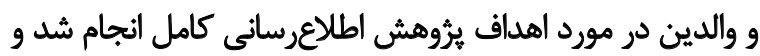

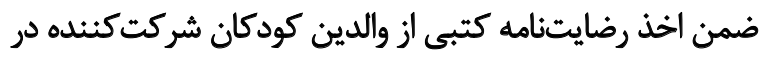

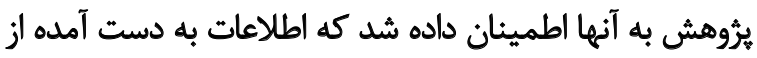

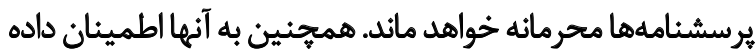

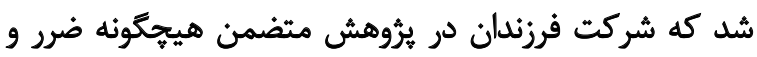

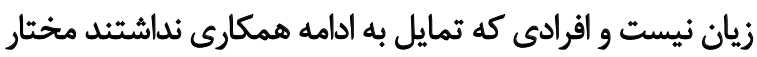

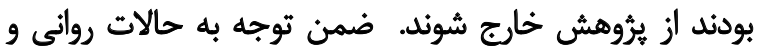

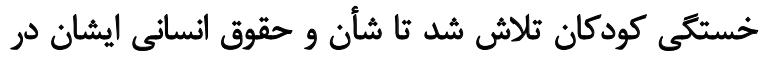

دارد و موجب افزايش كنترل خشم، كاهش مصرف مواد مخدر

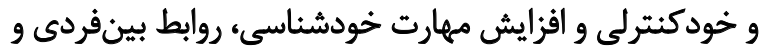
مديريت خشم در كودكان مى مئرد.

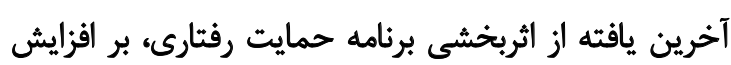

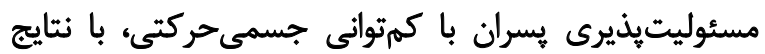

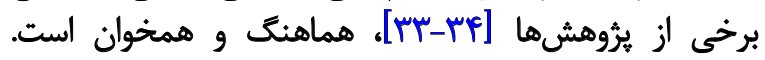

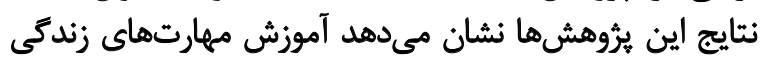

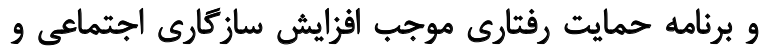

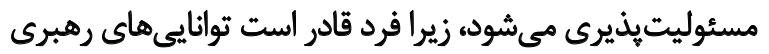

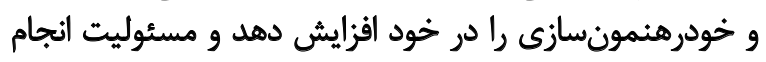

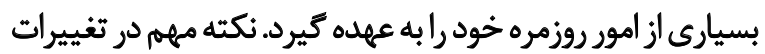

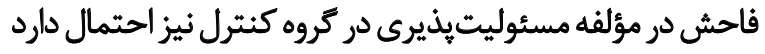

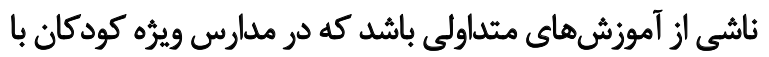

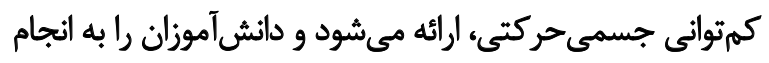

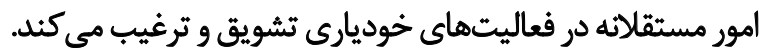

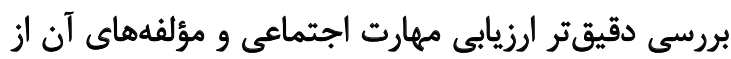

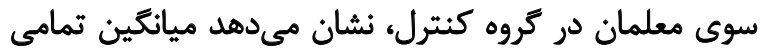

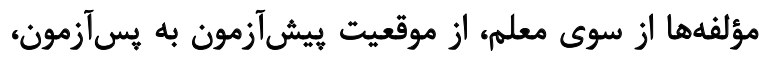

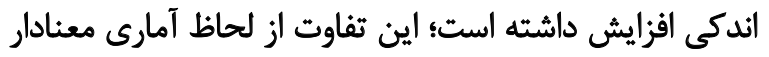

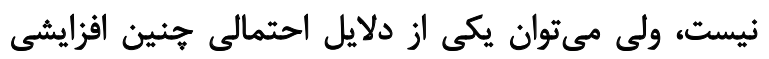

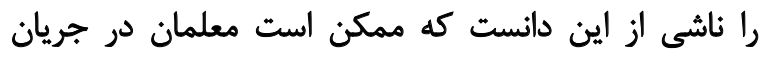

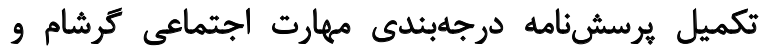

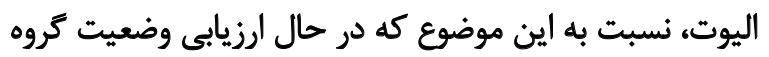

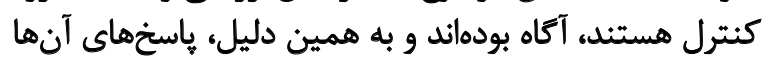

$$
\text { با سوكيرى همراه بوده است. }
$$

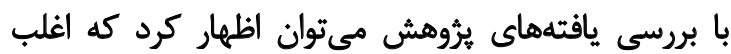

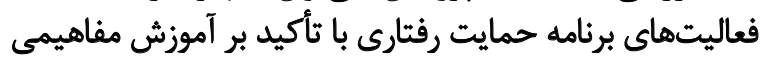

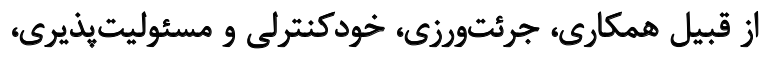

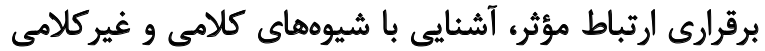

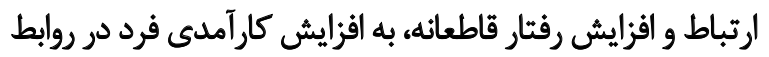

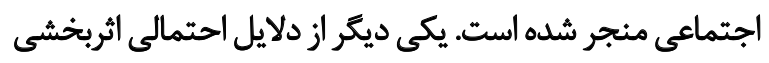

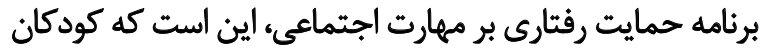

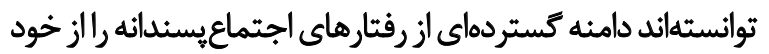

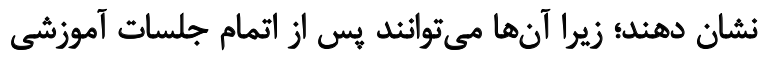

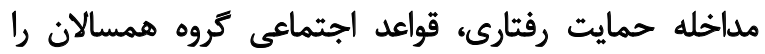

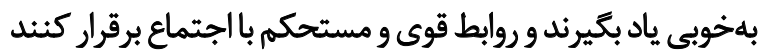

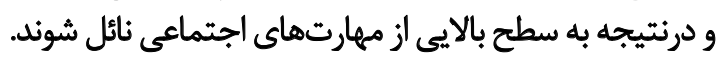

\section{تثيجليَّيرى}

با توجه به نثايج يثوهش حاضر مبنى بر ثأثيركذارى برنامه

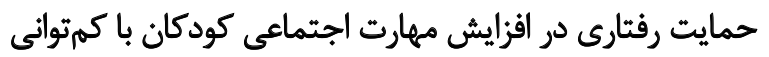

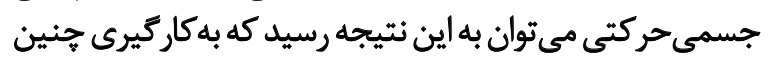

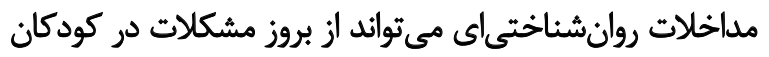


خلال يُؤوهش رعايت شود و يس از اتمام مداخله يك جلسه

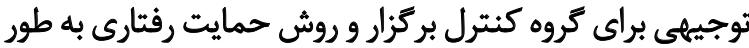
اجمالى براي ايشان توضيح داده شد.

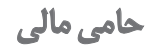

اين مقاله از باياننامه كارشناسىارشد رقيه طراح حامدانظام

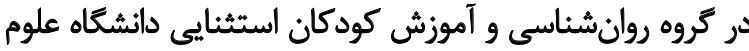

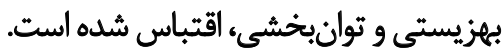

$$
\text { مشاركت نويسند مكان }
$$

مفهومسازى، ويراستارى و نهايیىسازى مقاله: معصومه

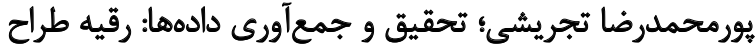
حامدنظام؛ كيتا موللى: مشاوره تنظئم مقاله

$$
\text { تعارض منافع }
$$

بنابر اظهار نويسندكان، اين مقاله تعارض منافع ندارد.

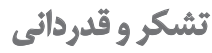

بدين وسيله از دانشكاه علوم بهزيستى و توانبخشى، به دليل

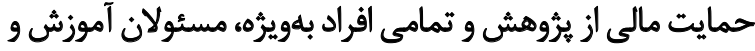

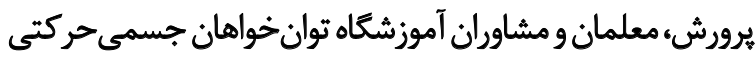

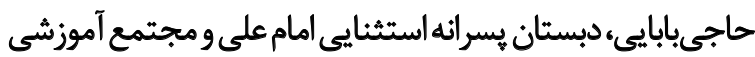

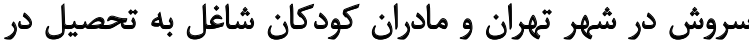

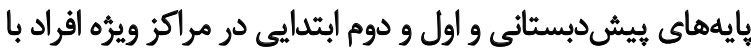

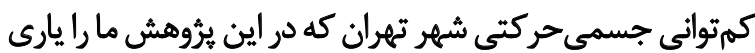

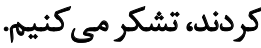




\section{References}

[1] Hallahan DP, Kauffman JM, Pullen PC. Exceptional learners: Introduction to special education. London: Pearson; 2014.

[2] King G, Specht J, Shultz I, Warr-Leeper G, Redekop W, Risebrough N. Social skills training for withdrawn unpopular children with physical disabilities: A preliminary evaluation. Rehabilitation Psychology. 1997; 42(1):47-60. [DOI:10.1037//0090-5550.42.1.47]

[3] Della Fina V, Cera R, Palmisano G. The United Nations convention on the rights of persons with disabilities: A commentary. New York: Springer International Publishing; 2017.

[4] Lucas-Carrasco R, Eser E, Hao Y, McPherson KM, Green A, Kullmann L, et al. The Quality of Care and Support (QOCS) for people with disability scale: Development and psychometric properties. Research in Developmental Disabilities. 2011; 32(3):1212-25. [DOI:10.1016/j.ridd.2010.12.030] [PMID]

[5] Parkes J, White-Koning M, Dickinson HO, Thyen U, Arnaud C, Beckung $E$, et al. Psychological problems in children with cerebral palsy: a cross-sectional European study. Journal of Child Psychology and Psychiatry. 2008; 49(4):405-13. [DOI:10.1111/ j.1469-7610.2007.01845.x] [PMID]

[6] Jalili N, Akbar Fahimi N, Hosseini SA, Farzi M, Falsafian R. [Behavioral problems in children with cerebral palsy (Persian)]. Archives of Rehabilitation. 2012; 12(4):30-7.

[7] Appleton PL, Minchom PE, Ellis NC, Elliott CE, Böll V, Jones P. The self-concept of young people 'with spina bifida: A population-based study'. Developmental Medicine and Child Neurology. 1994; 36(3):198-215. [DOI:10.1111/j.1469-8749.1994. tb11833.x] [PMID]

[8] Mirkhani S, Hemmati F. [The principles of rehabilitation (Persian)]. Tehran: University of Social Welfare and Rehabilitation Sciences Publication; 2006

[9] Moradi A, Kalantari M, Moatamedi MS. [The role of demographic variables in predicting mental health among the physically disabled in Isfahan City (Persian)]. Quarterly of Knowledge and Research in Applied Psychology. 2006; 9(31):83-100.

[10] Cottrell RP. COTA to OTR: Factors influencing professional development. American Journal of Occupational Therapy. 2000; 54(4):413-20. [DOI:10.5014/ajot.54.4.413] [PMID]

[11] Christophersen ER, Van Scoyoc SM. Treatment that work with children: Empirically supported strategies for managing childhood problems. Washington: American Psychological Association; 2013. [DOI:10.1037/14137-000]

[12] Gresham FM, Watson TS, Skinner CH. Functional behavior assessment: Principles, procedures and future directions. School Psychology Review. 2001; 30(2):156-72.

[13] Asher SR, Taylor AR. Social outcomes of mainstreaming: Sociometric assessment and beyond. Exceptional Education Quarterly. 1981; 1(4):13-30. [DOI:10.1177/074193258100100407]

[14] Shalchi B, Vahidnia B, Dadkhah M, Alipour Niaz M, Moghimifam P. [Comparison of affective-behavioral disorders and social skills among normal adolescents and institutional chil- dren of Social Welfare Bureau (Persian)]. Social Welfare. 2017; 17(67):173-201.

[15] Karami B, Gashool M, Tayarani Rad A, Qasemi S. The Matson Evaluation of Social Skills with Youngsters-III (MESSY-II) and its adaptation for Iranian children and adolescents with intellectual disability. Practice in Clinical Psychology. 2013; 1(4):23945.

[16] Maziak W, Asfar T, Mzayek F, Fouad FM, Kizieh N. Sociodemographic correlates of psychiatric morbidity among lowincome women in Aleppo, Syria. Social Science \& Medicine. 2002; 54(9):1419-27.[DOI:10.1016/S0277-9536(01)00123-X]

[17] Maclnnes DL. Self-esteem and self-acceptance: An examination into their relationship and their effect on psychological health. Journal of Psychiatric and Mental Health Nursing. 2006; 13(5):483-9. [DOI:10.1111/j.1365-2850.2006.00959.x] [PMID]

[18] Spencer T. The role of research in the lives of people with disabilities: Too little too late? American Academy of Developmental Medicine and Dentistry. Boston: Exceptional Parent Magazine; 2007.

[19] Maltby J, Day L, McCutcheon LE, Gillett R, Houran J, Ashe DD. Personality and coping: A context for examining celebrity worship and mental health. British Journal of Psychology. 2004; 95(4):411-28. [DOI:10.1348/0007126042369794] [PMID]

[20] Akhavan Tafti M, Mofradnezhad N. [The relationship of emotional intelligence and social skills with psychological well-being in the elderly (Persian)]. Iranian Journal of Ageing. 2018; 13(3):334-45. [DOI:10.32598/sija.13.3.334]

[21] Gardner RM, Bird FL, Maquir H, Carreiro R, Abenaim N. Intensive positive behavior supports for adolescents with acquired brain injury: Long-term outcomes in community settings. The Journal of Head Trauma Rehabilitation. 2003; 18(1):52-74. [DOI:10.1097/00001199-200301000-00007]

[22] McGee GG, Morrier MJ, Daly T. An incidental teaching approach to early intervention for toddlers with autism. Journal of the Association for Persons with Severe Handicaps. 1999; 24(3):133-46. [DOI:10.2511/rpsd.24.3.133]

[23] Gettinger M, Stoiber KC. Functional assessment, collaboration, and evidence-based treatment: Analysis of a team approach for addressing challenging behaviors in young children. Journal of School Psychology. 2006; 44(3):231-52. [DOI:10.1016/j.jsp.2006.03.001]

[24] Campbell SB. Behavior problems in preschool children: A review of recent research. Journal of Child Psychology and Psychiatry. 1995; 36(1):113-49. [DOI:10.1111/j.1469-7610.1995. tb01657.x] [PMID]

[25] Sugai G, Horner RH. Responsiveness-to-intervention and school-wide positive behavior supports: Integration of multitiered system approaches. Exceptionality. 2009; 17(4):223-37. [DOI:10.1080/09362830903235375]

[26] Sadri Damirchi E, Esmaelie Ghazi Velouee F. [Effectiveness of social-emotional skills training on cognitive emotion regulation and social skills in children with learning disabilities (Persian)]. Journal of Learning Disabilities. 2016; 5(4):59-86. 
[27] Fox L. Technical Assistance Center on Social-Emotional Interventions for young children (TACSEI). California: California MAP to Inclusion \& Belonging; 2016.

[28] McIntosh K, Ty SV, Miller LD. Effects of school-wide positive behavioral interventions and supports on internalizing problems. Journal of Positive Behavior Interventions. 2014; 16(4):209-18. [DOI:10.1177/1098300715599737]

[29] Jalil-Abkenar SS, Ashouri M, Pourmohammadreza-Tajrishi $M$. [Investigation of the effectiveness of social competence instruction on the adaptation behavior in boy students with intellectual disability (Persian)]. Archives of Rehabilitation. 2013; 13(Special Issue):104-13.

[30] Botvin GJ, Griffin KW, Diaz T, Miller N, Ifill-Willians M. Smoking imitation and escalation in early adolescent girls: one-year follow-up of a school-based prevention intervention for minority youth. Journal of American Medical Women's Association. 1999; 54:139-43.

[31] Hajizadehanari K, Haji Seyed Hossini Fard SM, Hajizadehanari $H$, Yaghoubzadeh A, Farhadian A, Askari M. The effectiveness of life skills education with religious approach to safety, mental health and self-esteem in elementary school students. The European Journal of Social and Behavioral Sciences. 2013; elSSN(2301-2218):928-37. [DOI:10.15405/ejsbs.67]

[32] Sheikhmohammadi A, Arjmandnia AA, Hasanzadeh S, Mirhesari AR. [The effectiveness of social competence-based program in enhancement social skills of student with learning disabilities (Persian)]. Journal of Exceptional Children. 2014; 14(3):19-30.

[33] Mahvashe Wernosfaderani A, Adibsereshki N, Movallali G. [The effectiveness of life skills training on the social skills of hearing impaired secondary school students in inclusive schools (Persian)]. Journal of Research in Rehabilitation Sciences. 2012; 8(3):477-88.

[34] Hyatt KH, Filler YW. A comparison of the effects of two social skill training approaches on teacher and child behavior. Journal of Research in Childhood Education. 2007; 22(1):85-96. [DOI:10.1080/02568540709594614]

[35] Bakhshi-Barzili $M$, Pourmohamadreza-Tajrishi M, AdibSereshki N, Mikaeili E. [The effect of theory of mind training on social skills improvement in intellectually disabled students (Persian)]. Archives of Rehabilitation. 2013; 14(2):61-9.

[36] Eslami AA, Amidi Mazaheri M, Mostafavi F, Abbasi MH, Moroozi E. Farsi version of social skills rating system-secondary student form: Cultural adaptation, reliability and construct validity. Iranian Journal of Psychiatry and Behavioral Sciences. 2014; 8(2):97-104. [PMID] [PMCID]

[37] Flanagan DP, Alfonso VC, Primavera LH, Povall L, Higgins D. Convergent validity of the BASC and SSRS: Implications for social skills assessment. Psychology in the Schools. 1996; 33(1):1323. [DOI:10.1002/(SICI)1520-6807(199601)33:13.0.CO;2-X]

[38] Shahim S. [Standardization of social skills rating system for preschool children (Persian)]. Iranian Journal of Psychiatry and Clinical Psychology. 2005; 11(2):176-86.

[39] Behpazhouh A, Hejazi E, Hossein Khanzadeh AA, Ghobari Bonab B. [A comparison of social skills of partially hearing impaired students in integrated versus nonintegrated schools (Persian)]. Quarterly Journal of Psychology and Education. 2006; 35(2):63-83.

[40] Jafarinejad Fard Kohan M, Ghobary Bonab B. [Social skills and academic achievement in exceptional students in integrated and regular schools (Persian)]. Journal of Exceptional Children. 2009; 9(1):63-73.

[41] Gage NA, Sugai G, Lewis TJ, Brzozowy S. Academic achievement and school-wide positive behavior supports. Journal of Disability Policy Studies. 2015; 25(4):199-209. [DOI:10.1177/1044207313505647]

[42] Aazami Y, Sohrabi F, Borjali A, Farrokhi N, Farokh Forghani $S$. [The effectiveness of psychosocial model-based therapy on social skills in people with PTSD after burn (Persian)]. Archives of Rehabilitation. 2018; 19(3):206-19. [DOI:10.32598/ rj.19.3.206]

[43] Roshan Chesli R. [Effect of social competence training-based storytelling on social skills and behavioral problems of 8-10 year-old children with Oppositional Defiant Disorder (ODD) (Persian)]. Quarterly of Clinical Psychology Studies. 2013; 3(10):73-94. 
This Page Intentionally Left Blank 